\section{QUANTIFICAÇÃO DE CHUMBO EM SOLOS: UM ESTUDO COMPARATIVO ENTRE ÁREAS DE FALHA GEOLÓGICA E ÁREAS RURAIS NA CIDADE DE PRESIDENTE PRUDENTE/SP}

\section{MEASUREMENT OF LEAD IN SOIL: A COMPARAIVE STUDY BETWEEN AREAS OF GEOLOGICAL FAULT AND RURAL AREAS IN THE CITY OF PRESIDENTE PRUDENTE/SP}

Marcos Roberto Moreira da Silva Junior ${ }^{1}$, Carlos Alberto Tello Sáenz ${ }^{2}$, João Osvaldo Rodrigues Nunes ${ }^{3}$, Marcos Fernando de Souza Teixeira ${ }^{4}$

Universidade Estadual Paulista, Faculdade de Ciências e Tecnologia, Departamento de Física, Química e Biologia ${ }^{1,2,4}$, e Departamento de Geografia ${ }^{3}$. E-mail: silva.mrm@hotmail.coml, funcao@fct.unesp.br

RESUMO - O objetivo desse trabalho foi a quantificação de $\mathrm{Pb}$ em amostras de solos, em áreas específicas na cidade de Presidente Prudente-SP, onde a particularidade do meio físico é o indício de uma falha geológica. Coletaram-se amostras em áreas pré-estabelecidas do Campus da FCT - UNESP, conforme dados referentes à emanação de Rn, e também perfis de solos no Distrito de Montalvão. Utilizou-se a técnica voltamétrica de redissolução anódica com eletrodo de mercúrio para a quantificação de $\mathrm{Pb}$, que mostrou-se satisfatória e com baixo limite de deteç̧ão. A concentração de $\mathrm{Pb}$ nas amostras de solo coletadas na área rural foi cem vezes menor que na área de suposta falha geológica, gerando a hipótese de influência da emanação de $\mathrm{Rn}$ quanto ao teor de $\mathrm{Pb}$ nessas áreas. Análises granulométricas e imagens do MEV foram usadas para estudo e caracterização das amostras de solos.

Palavras-chave: $\mathrm{Pb}$; falha geológica; técnica voltamétrica.

ABSTRACT - The objective of this work was the quantification of lead $(\mathrm{Pb})$ in soil samples in specific areas in the city of Presidente Prudente$\mathrm{SP}$, where one of the features of the physical environment of this region is its proximity to areas with strong evidence of a geological fault. Samples were collected at pre-established regions according to the data regarding the emanation of $\mathrm{Rn}$, and also collected soil profiles in the district of Montalvão. Analyzes of $\mathrm{Pb}$ using the anodic stripping voltammetry with mercury electrode was satisfactory and proved to have a low detection limit. The concentration of $\mathrm{Pb}$ were one hundred lesser in soil samples collected in rural areas, generating the hypothesis of influence of emanation of $\mathrm{Rn}$ in $\mathrm{Pb}$ concentration. The granulometry analyzes and MEV were used to characterization soils samples.

Keywords: Pb; geological fault; voltammetry.
Recebido em: 27/08/2014

Revisado em: 30/08/2014

Aprovado em: 30/08/2014 


\section{INTRODUÇÃO}

Devido ao solo ser conceituado como um sistema bastante diversificado, são inúmeras suas definições, que podem variar de acordo com o contexto empregado. Alguns autores definem o solo como sendo um produto da ação do intemperismo nas rochas, e que sob a influência do tempo e fatores como clima, topografia, vegetação e atividades de micro-organismos é passível à evolução. Segundo Teixeira (2000), o solo é considerado um recurso de grande importância para o planeta, e justamente por ser um recurso não renovável deve ser gerenciado adotando-se conhecimentos científicos com a finalidade de preservá-lo.

$\mathrm{Na}$ composição dos solos inclui-se materiais orgânicos e inorgânicos, onde estão inseridos os minerais. A matéria mineral que constitui o solo tem origem na rocha parental. Durante $\mathrm{o}$ processo de alteração da rocha e de formação do solo, os minerais oriundos da rocha podem ser transformados em outros minerais, podem ser completamente perdidos ou até mesmo resistirem ao processo e manterem-se semelhantes à composição da rocha parental.

No Brasil, a necessidade em promover estudos mais criteriosos em relação a classificação dos solos, elaborou-se um
Sistema Brasileiro de Classificação de Solos (SiBCS), coordenado pela Embrapa (2006).

Segundo Ross e Moroz (1996) e o Mapa Pedológico do estado de São Paulo, identificou-se aproximadamente oito tipos de solos na região do oeste paulista, onde os mais representativo no município de Presidente Prudente são os Argissolos Vermelhos e os Latossolos Vermelhos, resultado de processos pedogênicos ocorridos em rochas areníticas do Grupo Bauru. Estudos recentes realizados no município de Presidente Prudente/SP por Fushimi e Nunes (2012) indicam que Latossolos Vermelhos apresentam-se principalmente nos topos suavemente ondulados das colinas, os Argissolos Vermelhos em colinas de topos menos extensos, os Neossolos Regolíticos predominam em vertentes mais íngremes, nos fundos de vales identificam-se solos hidromórficos do tipo Planossolos, Gleissolos e os Antropossolo.

A região de Presidente Prudente/SP apresenta fortes indícios da localização e direção de falhas geológicas soterrada a aproximadamente $200 \mathrm{~m}$ de profundidade sendo uma característica marcante de regiões onde há fontes geotérmicas, de acordo com Balcazar et al. (1993). É muito provável que essas falhas estejam vinculadas com outras, que se mostram na superfície através de córregos, existentes na cidade de 
Presidente Prudente/SP, que por sua vez podem estar ligadas a falhas mais importantes que atravessam praticamente todo o interior do estado de São Paulo.

Falha geológica é uma descontinuidade das estruturas planares entre blocos de rocha, os quais apresentam movimentos relativos entre si. É o resultado de extensão, distensão ou torção. Suas dimensões variam da escala mineralógica às escalas continentais. Para Ramsay e Huber (1987), na realidade geológica, o que se observa é um conjunto de estruturas que representa o momento final de um complexo processo evolutivo na escala do tempo geológico, em que há o contínuo incremento nas deformações. Em uma região onde há vários planos de falhas paralelos ou entrelaçados, denomina-se zona de falha.

O crescente número de pesquisas voltadas aos estudos do radônio (Rn), está ligado ao fato do mesmo ser um gás inerte e possuir certa facilidade de escapar do mineral onde está contido e se difundir à fase fluida circundante como águas subterrâneas e ar, emitindo radiação, principalmente em regiões de falhas geológicas, dando origem a outros elementos, subprodutos de seu decaimento. Os subprodutos emitidos, comumente chamados de filhos de radônio, por serem metálicos e consequentemente reativos e possuírem características físicas que permitem diferentes comportamentos frente à variação de temperatura e pressão, fazem com que os mesmos fiquem aderidos a aerossóis em suspensão se difundindo para locais distantes daquele de origem, ocasionando emissão de radiações alfa e beta na sequência de decaimentos no meio ambiente.

Quando se trata da periculosidade dos filhos de radônio, em especial o $\mathrm{Pb}, \mathrm{a}$ literatura traz, segundo Baird (2002), que o mesmo, normalmente está atrelado aos efeitos no meio ambiente e também aos efeitos na saúde onde apresenta um caráter tóxico significativo.

A Figura 1 ilustra a série de decaimento do urânio (U), na qual o radônio $(\mathrm{Rn})$ se insere, relacionando o decaimento ( $\alpha$ ou $\beta$ ) de cada elemento até o chumbo (Pb).

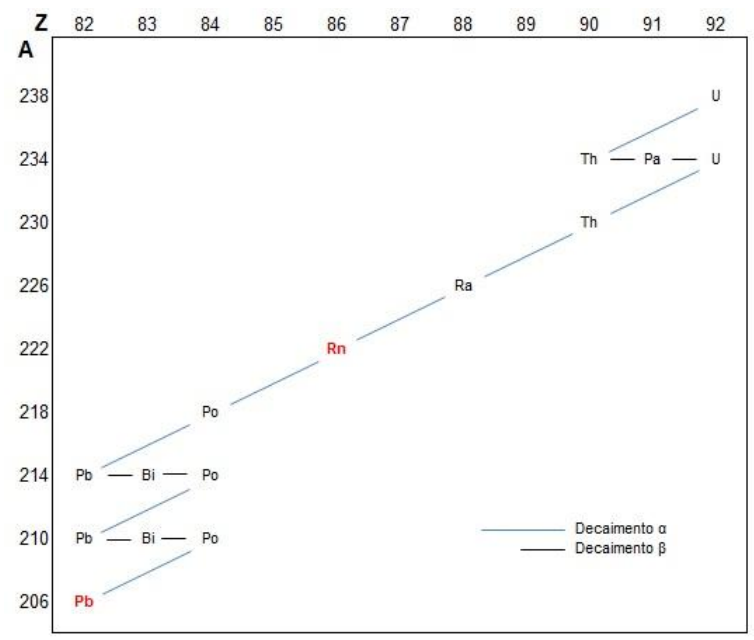

Figura 1. Série radioativa do urânio. Fonte: (Adaptado de UNSCEAR, 2000)

Objetivou-se com esse trabalho, a quantificação de chumbo (Pb) em amostras de solos e sua relação em áreas específicas 
na cidade de Presidente Prudente, interior do estado de São Paulo, onde uma das particularidades da área é o indício de falhas geológicas com elevado índice de emanação de Rn.

\section{METODOLOGIA}

\subsection{Local e coleta das amostras de solo}

As amostras foram coletadas em duas áreas distintas da cidade de Presidente Prudente/SP. A primeira na área urbana, dentro do Campus FCT - UNESP, onde estudos prévios determinaram uma grande variabilidade da emanação de gás radônio (Rn). A segunda área de estudo localizada na área rural da cidade de Presidente Prudente$\mathrm{SP}$, mais precisamente no Distrito de Montalvão, apresentava cobertura vegetal do tipo gramínea. A área faz parte de uma propriedade privada, chácara São José, e encontra-se inutilizada tanto para agricultura quanto para pecuária há pelo menos dez anos, indicando pouca influência antropogênica, conforme relatos do proprietário.

Na primeira área foram coletados seis amostras de solos, todas em 60 centímetros de profundidade, denominadas de ponto 1 (P1), ponto 2 (P2), ponto 3 (P3), ponto4 (P4), ponto 5 (P5) e ponto 6 (P6) seguindo os dados indicativos de emanação de $\mathrm{Rn}$. O método de amostragem de solos, do tipo amostras deformadas, foi baseado nos procedimentos adotados pela CETESB. Para garantir a integridade química e mineralógica do solo coletado, utilizou-se trado do tipo caneco onde as amostras foram acondicionadas imediatamente após a sua retirada do perfil do solo, e tomou-se o cuidado em coletar apenas o solo contido na região central do trado. Foi realizado o manuseio da amostra com cautela para não arrastar o solo fixado nas paredes do trado, evitando qualquer contaminação. As amostras foram armazenadas em recipientes de tampa hermética e esterilizados, que foram devidamente identificados.

$\mathrm{Na}$ segunda área, optou-se pelo método de coleta de amostras indeformadas, pois assim foi possível manter a estrutura original do perfil do solo coletado. A coleta foi realizada utilizando-se de tubos de policloroetano com diâmetro de quatro polegadas, e setenta centímetros de comprimento onde em um dos extremos afunilou-se a parede do tubo para facilitar a cravação no solo e no extremo oposto, a cinco centímetros da borda, foram feitos dois furos para facilitar a retirada do tubo quando inserido no perfil do solo, por meio de uma corda, conforme Figura 2. 


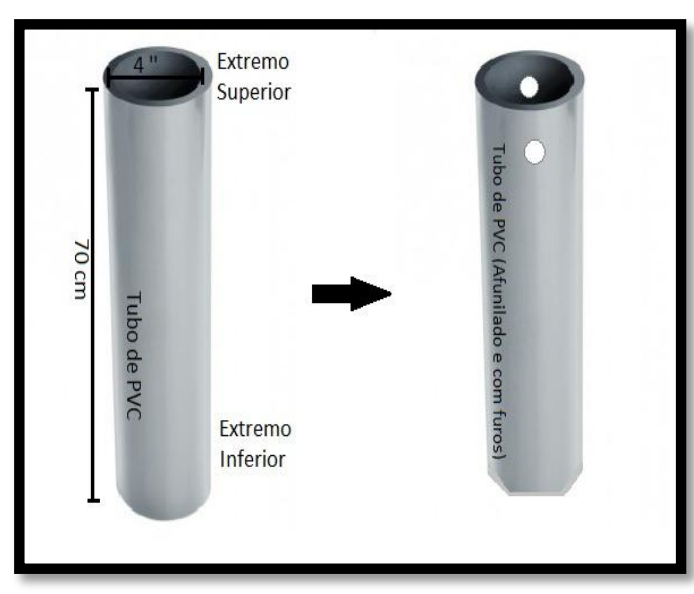

Figura 2. Dimensões do tubo de PVC.

O tubo foi inserido no solo, de forma vertical, na intenção de coletar um perfil de até $60 \mathrm{~cm}$ de profundidade utilizando como apoio uma viga de madeira e martelo Com auxílio de enxada e pá, retirou-se o solo que envolvia externamente o tubo cravado no perfil, para facilitar sua retirada. Passou-se uma corda nos furos do extremo superior do tubo de PVC, e cuidadosamente deslocou-se o tubo que foi retirado com auxílio de uma enxada, usada como base para evitar a perda do solo pelo extremo inferior do tubo.

Os tubos de PVC contendo o perfil do solo, foram devidamente envoltos por saco plástico para evitar ruptura e facilitar transporte até o laboratório onde foram abertos (realizou-se cortes no sentido horizontal do cano de PVC, dividindo-os em duas partes iguais). Posterior abertura dos tubos, foram coletadas amostras no horizonte de 60 centímetros.

\subsection{Pré-tratamento das amostras de solos}

As amostras de solo foram secas em estufa durante 24 horas em temperatura de aproximadamente $100{ }^{\circ} \mathrm{C}$, posteriormente maceradas em cadinho de porcelana e quarteadas afim de obtenção de três amostras representativas. Cada amostra foi submetida ao procedimento de digestão ácida baseado no método USEPA 350 (1988) com algumas modificações. Consistiu na digestão da amostra de solo $(0,5 \mathrm{~g})$ em $10 \mathrm{~mL}$ de $\mathrm{HNO}_{3} 65 \%(\mathrm{v} / \mathrm{v})$, dispostos em tubos de digestão onde foram abertos por 120 minutos a $98^{\circ} \mathrm{C}$, em bloco digestor. Após este período as amostras foram resfriadas por 30 minutos e então adicionado a elas $10 \mathrm{~mL}$ de $\mathrm{H}_{2} \mathrm{O}_{2} 30 \%(v / v)$. Após cessar a efervescência, mantiveram-se em repouso por um período de 180 minutos. Após esse intervalo, foram aquecidas novamente no bloco digestor por 2 horas a $98^{\circ} \mathrm{C}$. Por fim, as amostras foram resfriadas e adicionou-se $5 \mathrm{~mL}$ de $\mathrm{HCl} 38 \%$ $(v / v)$. As amostras foram filtradas e armazenadas em recipiente plástico previamente esterilizado.

\subsection{Otimização dos parâmetros experimentais}

\subsubsection{Estudo da influência da variação do volume}

\section{da amostra}

A influência do volume de amostra sobre a resposta voltamétrica foi avaliada na faixa de 25 a $2500 \mu \mathrm{L}$ fixando o tempo de pré-concentração de $30 \mathrm{~s}$, acompanhando os 
valores de corrente de redissolução anódica para o chumbo $(\mathrm{E}=-0,4 \vee$ vs. $\mathrm{Ag} / \mathrm{AgCl})$

2.3.2 Estudo da influência do tempo de pré concentração

Avaliou-se o melhor tempo de préconcentração para acumulação do analito, para a solução de $\mathrm{Pb} 1,0 \times 10^{-9} \mathrm{~mol} \mathrm{L^{-1 }}$ no eletrodo de mercúrio aplicando-se um potencial de $-1,2 \mathrm{~V}$ vs. $\mathrm{Ag} / \mathrm{AgCl}$ em um intervalo de 0 a 540 s. A etapa de redissolução anódica utilizando a técnica voltamétrica de pulso diferencial foi realizada em um intervalo de potencial de $-0,6$ a $-0,2 \mathrm{~V}$ vs. $\mathrm{Ag} / \mathrm{AgCl}$. Nessa etapa, analisou-se o tempo ideal para promover a acumulação do metal na superfície do eletrodo, para que o mesmo difundisse no mercúrio, tornando a amálgama homogenia, a fim de proporcionar uma sensibilidade adequada para determinação do metal em baixa concentração.

\subsection{Análise voltamétrica das amostras de solo}

A partir dos estudos referentes às melhores condições operacionais, as amostras de solo foram analisadas quanto ao seu teor de chumbo via análise voltamétrica por redissolução anódica com pulso diferencial utilizando eletrodo de mercúrio no modo gota pendente, onde os metais foram depositados através da eletrólise de seus íons. As análises foram realizadas individualmente e em triplica, usando uma célula eletroquímica contendo um eletrodo de trabalho de mercúrio no modo gota pendente, um eletrodo de $\mathrm{Ag} / \mathrm{AgCl}(\mathrm{KCl} 3 \mathrm{M})$ como referência e um eletrodo auxiliar de platina (Pt).

Inicialmente adicionou-se à célula eletroquímica $20 \mathrm{~mL}$ de $\mathrm{NaNO}_{3}$, sendo o eletrólito suporte utilizado para as determinações de $\mathrm{Pb}$. Em seguida a solução foi borbulhada com nitrogênio por um período de 5 minutos. Com o potencial do eletrodo ajustado a um valor suficientemente negativo para reduzir os íons a sua forma metálica, a etapa de pré-concentração foi realizada sob agitação constante, em -1,2 V vs. $\mathrm{Ag} / \mathrm{AgCl}$ para concentrar os metais na superfície do eletrodo a partir de um volume de $2 \mathrm{~mL}$ de amostra, por 30 segundos.e em seguida, deixou-se a solução em repouso por alguns segundos para o sistema entrar em equilíbrio.

Após a etapa de pré-concentração, realizou-se uma varredura de potencial, em um intervalo de $-0,6$ a $-0,2 \mathrm{~V}$, e velocidade de varredura de $0.005 \mathrm{~V} \mathrm{~s}^{-1}$ no qual o analito $(\mathrm{Pb})$ foi redissolvido para a solução, devido à sua reoxidação, conforme Almeida (2003). Com isso, foi possível obter o valor da corrente de pico correspondente ao Pb. Para obtenção das curvas analíticas por adição múltipla de padrão, repetiu-se tal 
procedimento com sucessivas adições $1,0 \mu \mathrm{L}$ de solução padrão de $\mathrm{Pb} 1,00 \times 10^{-3} \mathrm{~mol} \mathrm{~L}^{-1}$.

\subsubsection{Estudo dos interferentes}

Para esse estudo, a concentração de $\mathrm{Pb}$ em solução foi fixa em $2,5 \times 10^{-7} \mathrm{~mol} \mathrm{~L}^{-1} \mathrm{e}$ variou-se a concentração dos interferentes em $2,5 \times 10^{-7}$ e $1,75 \times 10^{-6} \mathrm{~mol} \mathrm{~L}^{-1}$. Em seguida realizou-se a voltametria de redissolução anódica no intervalo de potencial -1,2 a 0,15 $\mathrm{V}$ vs. $\mathrm{Ag} / \mathrm{AgCl}$ em velocidade de varredura de $5 \mathrm{mV} \mathrm{s}^{-1}$.

\subsection{Análise granulométrica das} amostras de solo

A análise textural seguiu as normas do Manual de Métodos de Análises de Solos, utilizando o método da pipeta, de acordo com Embrapa (1999).

O método iniciou-se com o destorroamento do solo, onde as amostras foram secas ao ar por um período de 7 dias e em seguida realizou-se a moagem em almofariz com auxílio de um pistilo, até obtenção de amostras finamente moídas e homogêneas.

Pesou-se $10 \mathrm{~g}$ desse solo seco e moído em um erlenmeyer, e adicionou-se $20 \mathrm{~mL}$ de água destilada e $10 \mathrm{~mL}$ de uma solução de hidróxido de sódio $(\mathrm{NaOH}) 1 \mathrm{~mol} \mathrm{~L}^{-1}$. Os erlenmeyers foram agitados em mesa agitadora por 6 horas para desagregar os diferentes grãos que compõem o solo.
Depois da agitação, as soluções foram filtradas em peneira com abertura de $0,053 \mathrm{~mm}$, com auxílio de um funil, em provetas de $1000 \mathrm{~mL}$. Foram lavadas com água destilada até completar o volume de $1000 \mathrm{~mL}$, onde as frações de silte e argila ficaram depositadas. Nessa primeira etapa de filtração, todas as frações de areia ficaram retidas na peneira. Transferiu-se a areia para placas de Petri, previamente secas em estufa e pesadas. A areia foi mantida na estufa por 24 horas a $105^{\circ} \mathrm{C}$, e quando transcorrido este tempo foi resfriada em dissecador e então as placas de Petri contendo as areias foram devidamente pesadas e anotados seus valores

As provetas contendo argila e silte foram condicionadas em um tanque com água, para manter uma uniformidade térmica Com um termômetro foram aferidas as temperatura da solução e anotadas. Foram agitadas com um bastão de vidro por 30 segundos deixando um intervalo de 2 minutos para a agitação da amostra seguinte.

O inicio da agitação foi determinado como o tempo inicial (tempo zero), e quando finalizou o tempo de sedimentação iniciou-se a pipetagem de $5 \mathrm{~mL}$ da solução a $5 \mathrm{~cm}$ de profundidade da pipeta. A pipetagem foi realizada com um intervalo de tempo de 2 minutos entre uma amostra e outra, transferiu-se a alíquota para um béquer seco e previamente pesado, e foram deixados 
secar em estufa por 24 horas a $105^{\circ} \mathrm{C}$. Transcorrido este tempo e resfriados em dissecador, pesou-se as massas dos béqueres com a argila.

Os valores das massas foram devidamente anotados para obtenção dos resultados das frações de areia, silte e argila de cada amostra de solo.

\subsection{Caracterização morfológica via}

\section{Microscopia Eletrônica de Varredura}

As imagens das amostras de solos foram obtidas através de Microscópio Eletrônico de Varredura (MEV) Carl Zeiss modelo EVO LS15 equipado com detector de elétrons secundários (SE) em alto vácuo e temperatura constante.

\section{RESULTADOS}

\subsection{Local e coleta das amostras de solo}

Foram coletadas seis amostras em diferentes pontos (P1, P2, P3, P4, P5, P6) dentro da extensão da primeira área de estudo propostas e coletados dois perfis de solos, denominados de ponto 7 (P7) e ponto 8 (P8).

A Tabela 1 apresenta dados das coordenadas, altitude, número de traços contados e densidade de traços com os respectivos erros de medidas, dos pontos de 1 a 8.
Tabela 1. Dados gerais sobre os pontos de coleta.

\begin{tabular}{|c|c|c|c|c|c|}
\hline 总 & 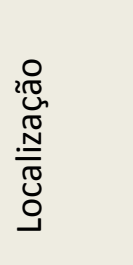 & $\begin{array}{l}\frac{n}{\pi} \\
\frac{\pi}{0} \\
\frac{\pi}{0} \\
\frac{0}{0} \\
\frac{1}{0} \\
0 \\
0\end{array}$ & 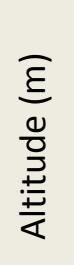 & 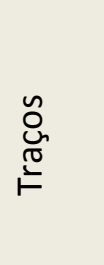 & 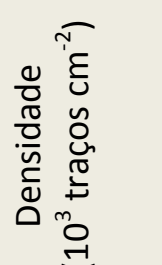 \\
\hline P1 & $\begin{array}{c}\text { FCT- } \\
\text { Unesp }\end{array}$ & $\begin{array}{l}0457811 / \\
7553372\end{array}$ & 449 & 1450 & $\begin{array}{c}1,16 \\
( \pm 2,62 \%) \\
\end{array}$ \\
\hline P2 & $\begin{array}{c}\text { FCT- } \\
\text { Unesp }\end{array}$ & $\begin{array}{l}0457376 / \\
7553392\end{array}$ & 448 & 1849 & $\begin{array}{c}1,38 \\
( \pm 2,33 \%) \\
\end{array}$ \\
\hline P3 & $\begin{array}{l}\text { FCT- } \\
\text { Unesp }\end{array}$ & $\begin{array}{l}0457811 / \\
7553475\end{array}$ & 441 & 2800 & $\begin{array}{c}2,10 \\
( \pm 1,89 \%) \\
\end{array}$ \\
\hline P4 & $\begin{array}{l}\text { FCT- } \\
\text { Unesp }\end{array}$ & $\begin{array}{c}0457749 / \\
7535626\end{array}$ & 446 & 1435 & $\begin{array}{c}1,24 \\
( \pm 2,64 \%)\end{array}$ \\
\hline P5 & $\begin{array}{l}\text { FCT- } \\
\text { Unesp }\end{array}$ & $\begin{array}{l}0457621 / \\
7553672\end{array}$ & 431 & 914 & $\begin{array}{c}0,84 \\
( \pm 3,31 \%)\end{array}$ \\
\hline P6 & $\begin{array}{l}\text { FCT- } \\
\text { Unesp }\end{array}$ & $\begin{array}{l}0457561 / \\
7553726\end{array}$ & 425 & 950 & $\begin{array}{c}0,74 \\
( \pm 3,24 \%)\end{array}$ \\
\hline P7 & $\begin{array}{c}\text { Distr. } \\
\text { Montal } \\
\text { vão }\end{array}$ & $\begin{array}{l}0220405 / \\
0511944\end{array}$ & 412 & - & - \\
\hline P8 & $\begin{array}{c}\text { Distr. } \\
\text { Montal } \\
\text { vão }\end{array}$ & $\begin{array}{c}0220404 / \\
0511943\end{array}$ & 413 & - & - \\
\hline
\end{tabular}

3.2 Estudo da influência da variação do volume da amostra

A influência do volume de amostra sobre a resposta voltamétrica foi avaliada na faixa de 25 a $2500 \mu \mathrm{L}$ fixando o tempo de pré-concentração de $30 \mathrm{~s}$, acompanhando os valores de corrente de redissolução anódica para o chumbo $(\mathrm{E}=-0,4 \mathrm{~V}$ vs. $\mathrm{Ag} / \mathrm{AgCl})$ conforme ilustra a Figura 3. 


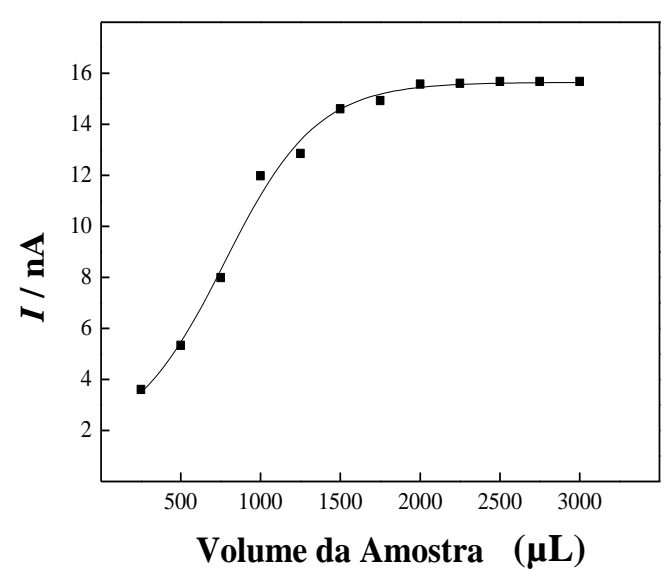

Figura 3. Influência da variação do volume da amostra.

3.3 Estudo da influência do tempo de concentração

O melhor tempo de pré-concentração para acumulação do metal $\mathrm{Pb}$ (II) no eletrodo de mercúrio aplicando um potencial de $-1,2 \mathrm{~V}$ em um intervalo de 30 a 540 segundos, adicionando $2 \mathrm{~mL}$ de amostra foi avaliado quando realizou-se a etapa de redissolução anódica utilizando a técnica voltamétrica de pulso diferencial em um intervalo de potencial de $-0,6$ a $-0,2 \mathrm{~V}$, conforme ilustra a Figura 4.

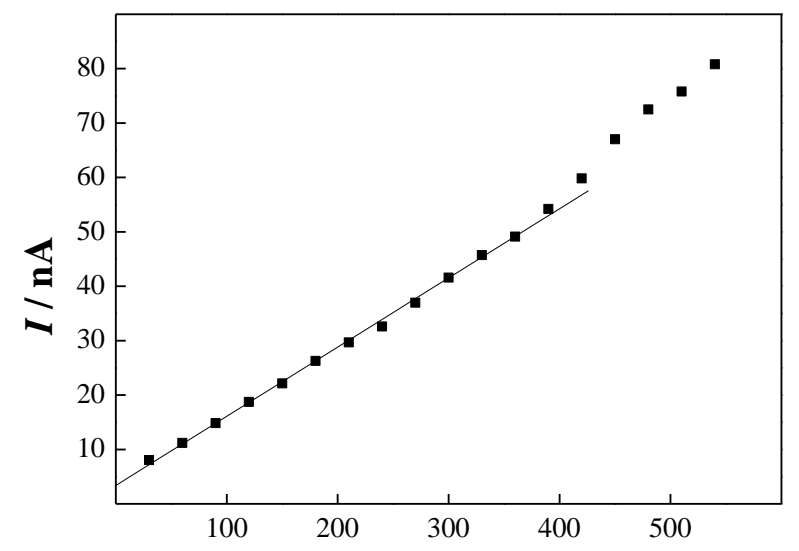

Tempo de pré-concentração

Figura 4. Influência do tempo de préconcentração.
3.4 Análise voltamétrica das amostras de solo

Os valores de corrente anódica referente à oxidação do $\mathrm{Pb}(-0,4 \mathrm{~V}$ vs. $\mathrm{Ag} / \mathrm{AgCl}$ ) geraram uma relação linear com a concentração padrão de metal adicionado no intervalo de $4,5 \times 10^{-8}$ a $1,2 \times 10^{-6} \mathrm{~mol} \mathrm{~L}^{-1}$, conforme ilustra a Figura 5, que representa a curva de calibração para $\mathrm{Pb}$ obtido pela voltametria de redissolução anódica pelo método de adição múltipla de padrão.

pré-

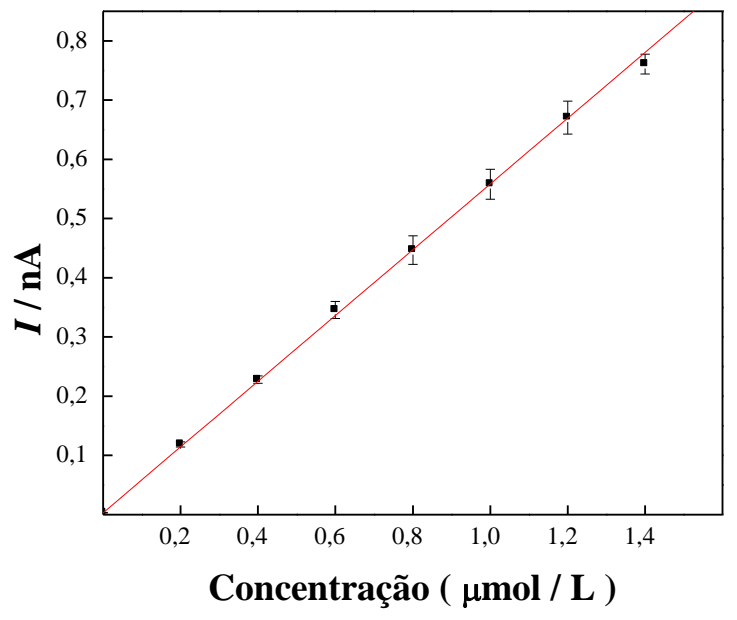

Figura 5. Concentração de $\mathrm{Pb}$ obtida pelo método de adição múltiplas de padrão.

Nas condições da faixa linear estimouse o limite de detecção, que é o menor valor de concentração de analito que corresponde ao menor sinal detectado com certeza razoável em um método analítico, e sensibilidade da técnica.

Os resultados obtidos a partir da análise quantitativa de $\mathrm{Pb}$ nos pontos de coleta das amostras de solo na área de suposta falha geológica, mostraram que sua 
concentração variou de 1,318 a 2,835 x 10-6 $\mathrm{mg} \mathrm{kg}^{-1}$, e o desvio padrão máximo correspondeu a 0,999, de acordo com a Tabela 2.

Tabela 2. Dados da concentraçõ de Pb, desvio padrão e coeficiente angular

\begin{tabular}{|c|c|c|c|}
\hline Ponto & [Pb] 10 $^{-6}$ & SD & $\mathbf{R}$ \\
\hline P1 & 1,491 & 0,479 & 0,999 \\
\hline P2 & 1,318 & 0,429 & 0,999 \\
\hline P3 & 1,565 & 0,865 & 0,999 \\
\hline P4 & 1,620 & 0,450 & 0,999 \\
\hline P5 & 1,645 & 0,183 & 0,999 \\
\hline P6 & 2,835 & 0,998 & 0,999 \\
\hline P7 & 0,034 & 3,775 & 0,998 \\
\hline P8 & 0,052 & 3,758 & 0,996 \\
\hline
\end{tabular}

\subsection{Estudo dos interferentes}

Amostras de solos, geralmente, apresentam valores de concentração na grandeza de ppm (partes por milhão) para o $\mathrm{Pb}$ e também para a maioria dos demais metais (Cd, Co, Cr, Cu, Hg, Mn, Ni e Zn) [76]. Para verificar o quanto esse método foi livre da ação de potenciais interferentes, efetuouse uma varredura para melhor observação da interação dos íons e a interferência desses na determinação de $\mathrm{Pb}$.

$\mathrm{Na}$ janela de potencial $-1,2$ a $0,15 \mathrm{~V}$ vs. $\mathrm{Ag} / \mathrm{AgCl}$, os possíveis interferentes foram $\mathrm{Zn}, \mathrm{Cd}$ e $\mathrm{Cu}$, conforme indicam os voltamogramas das Figuras de 5 a 7.
Observou-se que a análise de chumbo não é influenciada pela presença dos cátions metálicos $\mathrm{Zn}$ (II), Cd (II) e Cu (II).

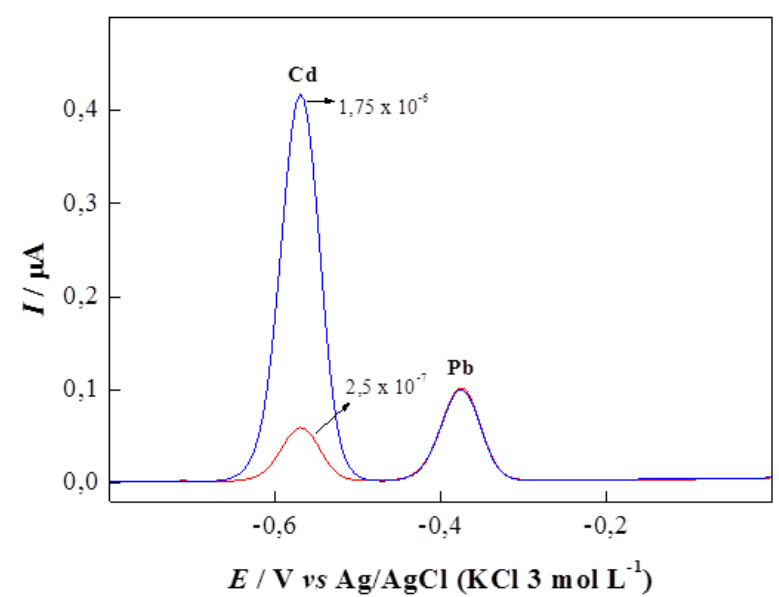

Figura 6. Voltamograma de $\mathrm{Pb}$ e $\mathrm{Cd}$.

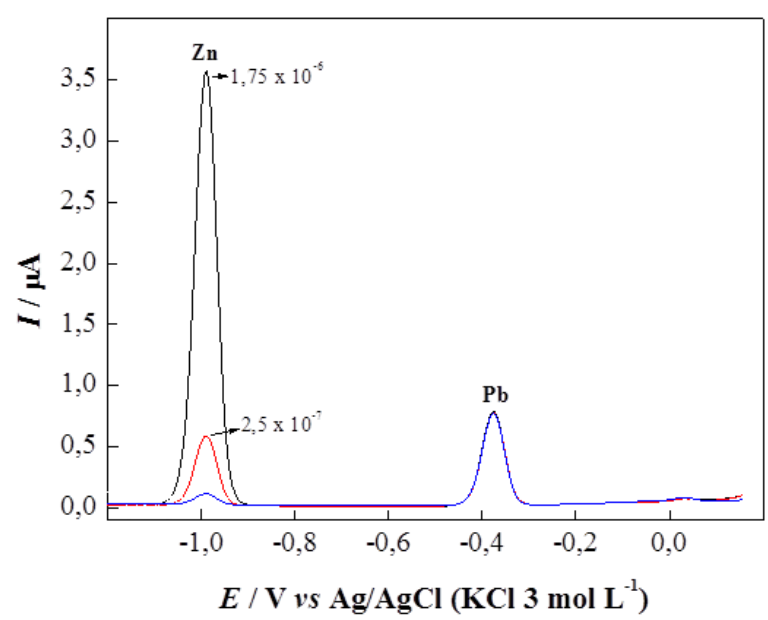

Figura 7. Voltamograma de $\mathrm{Pb}$ e $\mathrm{Zn}$.

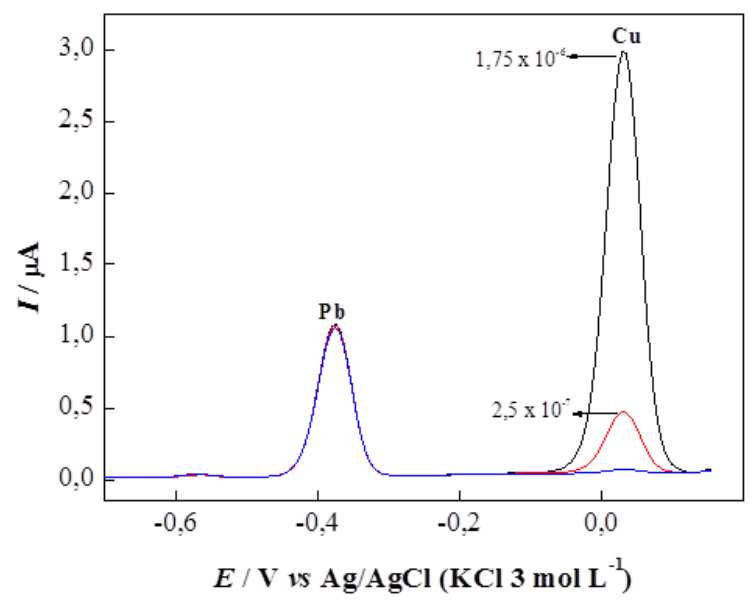

Figura 8 Voltamograma de $\mathrm{Pb}$ e $\mathrm{Cu}$. 
3.6 Análise granulométrica das

\begin{tabular}{|c|c|c|c|c|}
\hline Pontos & $\begin{array}{c}\text { Areia } \\
(\%)\end{array}$ & $\begin{array}{c}\text { Argila } \\
(\%)\end{array}$ & $\begin{array}{c}\text { Silte } \\
(\%)\end{array}$ & $\begin{array}{c}\text { Classe } \\
\text { textural }\end{array}$ \\
\hline P1 & 68,11 & 23,60 & 8,29 & $\begin{array}{c}\text { Franco Argilo } \\
\text { Arenono }\end{array}$ \\
\hline P2 & 72,65 & 17,00 & 10,35 & Franco Arenoso \\
\hline P3 & 61,34 & 28,40 & 10,26 & $\begin{array}{c}\text { Franco Argilo } \\
\text { Arenono }\end{array}$ \\
\hline P4 & 65,86 & 21,50 & 12,64 & $\begin{array}{c}\text { Franco Argilo } \\
\text { Arenono }\end{array}$ \\
\hline P5 & 67,97 & 21,80 & 10,23 & $\begin{array}{c}\text { Franco Argilo } \\
\text { Arenono }\end{array}$ \\
\hline P6 & 81,37 & 9,40 & 9,23 & $\begin{array}{c}\text { Franco Argilo } \\
\text { Arenono }\end{array}$ \\
\hline
\end{tabular}

amostras de solo

As análises granulométricas foram realizadas nas amostras $\mathrm{P} 1, \mathrm{P} 2, \mathrm{P} 3, \mathrm{P} 4, \mathrm{P} 5$ e P6. Foram obtidos as porcentagens de areia, argila e silte, conforme Tabela 3, possibilitando classificar as texturas dos solos baseando-se no triângulo textural adotado pela EMBRAPA.

Tabela 3. Porcentagens de areia, argila e silte.

\subsection{Microscopia Eletrônica de Varredura}

A morfologia das partículas que compõem as amostras de solo foi observada pelo MEV. Por possuírem frações de argila, areia e silte, observou-se nos solos estudados neste trabalho, a sedimentação de partículas grossas e finas simultaneamente, conforme Figura 9. 

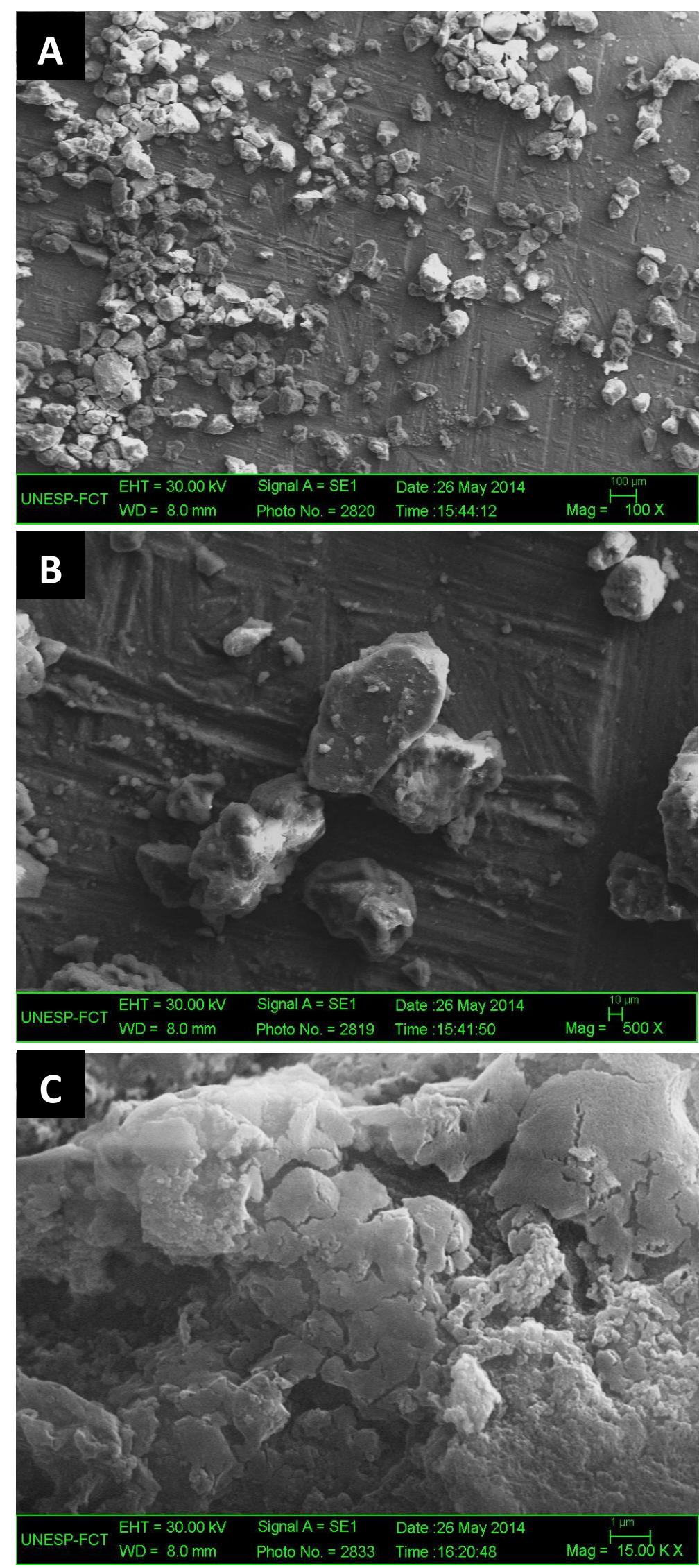

Figura 9. Imagens do MEV. 


\section{DISCUSSÕES}

\subsection{Local e coleta das amostras de solo}

Os resultados obtidos indicaram que a atividade de $\mathrm{Rn}$ na área de suposta existência de uma falha geológica é relativamente alta, sendo que as coletas compreenderam áreas entre as altitudes de $416 \mathrm{~m}$ e $450 \mathrm{~m}$ em relação ao nível do mar, justamente onde os detectores apresentaram os maiores valores de densidade de Rn.

Nesse contexto, surgiu a hipótese da existência de um falhamento geológico em forma de "S" ou de uma falha com várias ramificações.

\subsection{Estudo da influência da variação do volume da amostra}

De acordo com a Figura 3, a magnitude de corrente aumentou gradualmente com o acréscimo do volume da amostra, apresentando saturação para volumes superiores a $2000 \mu \mathrm{L}$ e não observou-se um aumento significativo do sinal de corrente.

Portanto, selecionou-se este valor como mais apropriado por apresentar uma boa repetibilidade dos sinais analíticos.

\subsection{Estudo da influência do tempo de pré-} concentração
Observou-se um incremento contínuo da corrente com o aumento do tempo de préconcentração, conforme Figura 4 e não observou-se nenhum patamar que indicasse uma magnitude máxima para um determinado tempo. Logo, o tempo de préconcentração de $30 \mathrm{~s}$ foi selecionado, por ser suficiente para a eletrodeposição dos íons e proporcionar mais dinamicidade as medidas.

\subsection{Análise voltamétrica das amostras de solo}

Nas condições da faixa linear estimouse o limite de detecção, que obedece à equação 1 .

$$
L D=\frac{3 S b}{b}
$$

onde $\boldsymbol{S}_{\boldsymbol{b}}$ é a estimativa do desvio padrão da média aritmética das concentrações obtidas de três voltamogramas de brancos e o $\boldsymbol{b}$ é o valor do coeficiente angular da reta de calibração obtido da curva analítica.

Os resultados mostraram que 0 método analítico utilizado provou ter um baixo limite de detecção de $0,0173 \mu \mathrm{mol} \mathrm{L}{ }^{-1} \mathrm{e}$ sensibilidade de 0,5521 sendo apto a ser empregado em análises de rotina.

Os resultados obtidos a partir da análise quantitativa de $\mathrm{Pb}$ nos pontos de coleta das amostras de solo, mostraram que sua concentração variou de 1,318 a 2,835 x $10^{-6} \mathrm{mg} \mathrm{kg}^{-1}$, e podem ser considerados relativamente altos para a área quando 
comparados, por exemplo, com estudos realizados às margens de estradas em regiões metropolitanas, onde as concentrações variaram entre 13,3 a 2,1 x $10^{-6} \mathrm{mg} \mathrm{kg}^{-1}$ e são considerados altos índices de concentração desse metal, justificáveis pelo intenso tráfego rodoviário e grande volume de água de escorrimento superficial das rodovias que tais solos foram influenciados, de acordo com Melo (2010).

O fato dos locais de coletas não apresentarem consideráveis fontes externas e antropogênicas de chumbo que justifiquem as altas concentrações encontradas, uma possível hipótese foi a origem desse metal decorrido da emanação de $\mathrm{Rn}$ (que tem como elemento mais estável o $\mathrm{Pb}$ ) que por sua vez pode ser indicativo também de um falha geológica.

A similaridade dos valores de concentração de $\mathrm{Pb}$ na área da FCT-UNESP indica uma estabilidade quanto à concentração de $\mathrm{Pb}$, não apresentando discrepâncias que poderiam estar envolvidas com ações antropogênicas, indicando que provavelmente possuem a mesma fonte natural do metal em análise.

A concentração de chumbo nessa área foi cerca de cem vezes maior que na área do Distrito de Montalvão.

Quando comparado a concentração de chumbo em áreas rurais da Austrália em um trabalho de Olszowy et al. (1995), onde quantificou-se até $14 \mathrm{mg} \mathrm{Kg-}{ }^{1}$, com área de Montalvão, foi possível perceber quão livre do metal a área se encontra. Esse resultado possibilitou a utilização desses perfis de solo como comparativo com os solos analisados na área de suposta falha geológica.

\subsection{Estudo dos interferentes}

$\mathrm{Na}$ janela de potencial $-1,2$ a $0,15 \mathrm{~V}$ vs. $\mathrm{Ag} / \mathrm{AgCl}$, os possíveis interferentes foram $\mathrm{Zn}, \mathrm{Cd}$ e $\mathrm{Cu}$, e conforme indicam os voltamogramas não existem diferenças significativas nos valores de corrente e deslocamento de potencial para a determinação do analito em interesse $(\mathrm{Pb})$. Ao realizar as adições das soluções interferentes, pode-se observar seus respectivos potenciais no intervalo estudado (Figuras 5 a 7), porém não apresentaram interferências quanto às correntes de pico do $\mathrm{Pb}$

\subsection{Análise granulométrica}

Os dados da análise granulométrica revelaram que os solos são caracterizados por porcentagens relativamente altas da fração areia, conforme dados da Tabela 4, classificando-os em classes texturais Franco Arenoso e Franco Argilo Arenoso. Solos com alto teor de areia, geralmente, possuem baixa capacidade de retenção de água haja vista sua alta taxa de drenagem. Em 
contrapartida, possuem boa aeração e uma propriedade intrínseca de rápida decomposição da matéria orgânica e alto potencial de lixiviação de poluentes. Existem poucos dados sobre a perda de chumbo no perfil do solo por lixiviação.

As porcentagens da fração argila variaram de 9,4 a $28,4 \%$ nos pontos de coletas de amostras. A concentração de chumbo nos solos pode variar em função da disponibilidade de húmus, matéria orgânica e argila, de acordo com Albert (1977), sendo o parâmetro argila o mais importante em solos tropicai. Segundo Xian (1989), mais de 43\% do chumbo presente no solo encontram-se na fração orgânica, sendo o restante ligado a outros componentes do sistema solo, como óxidos e hidróxidos de ferro e alumínio, carbonatos e fosfatos.

Se houver excesso de carga negativa na superfície do grão, pode acontecer uma atração dos cátions da fase líquida do solo, bem como de outros grãos. Este fenômeno de adsorção (ligação fraca e reversível de íons) é denominado de capacidade de troca de cátions (CTC). É natural, que as partículas com grande área superficial específica apresentem maior CTC. De fato, a CTC só é significativa nas partículas da fração argila. Nesse caso é possível que haja substituição de silício $\left(\mathrm{Si}^{+4}\right)$ e alumínio $\left(\mathrm{Al}^{+2}\right)$ por $\mathrm{Pb}^{+4} \mathrm{e}$ $\mathrm{Pb}^{+2}$ respectivamente, conforme estudos realizados por Alleoni et al. (2009).

\subsection{Microscopia Eletrônica de Varredura}

As partículas que se encontram na faixa de 2 a 0,05 mm são componentes da fração areia e possuem formato equidimensional, podendo variar em formas arredondadas, subarredondadas, subangulares, ou angulares, dependendo dos efeitos do ataque dos agentes mecânico conforme Santos, Grimaldi e Castro (2003), e podem ser observadas na Figura 9(a). Quando duas partículas de diâmetros menores que 0,02 $\mathrm{mm}$ se aderem, sedimentam-se simultaneamente e desta forma outras partículas podem unir-se ao grupo, formando aglomerados, conforme a Figura 9(b).

Esses aglomerados produzem uma estrutura muito frágil e solta, com grande volume de vazios, que podem ser ocupados por água e ar, onde o átomo de Rn pode ser incrustado e sofrer decaimento até o átomo de $\mathrm{Pb}$. As partículas menores que 0,0002 mm são pouco influenciadas pela força peso em comparação com as forças elétricas desenvolvidas entre as partículas e com as forças moleculares exercidas pela própria água. Seu tamanho muito pequeno resulta em alta área superficial específica, o que por sua vez permite que os desbalanços elétricos da estrutura se manifestem superficialmente

Nessa fração do solo a forma das partículas tende a ser achatada, onde as argilas em sua maior parte mostraram-se com formato laminar (Figura 9 (c)). Esse 
formato proporciona diferentes relações entre área e volume das partículas e, portanto, uma atividade superficial muito distinta, no que se refere à absorção de acordo com relatos de Chauvel (1979).

As cargas elétricas das partículas, principalmente da fração argila, podem neutralizar-se sob a influência da adição de íons de carga positiva oposta: um eletrólito por exemplo. Com suas cargas neutralizadas, chocam-se entre si, mantendo unidos pelas forças de aderência que se desenvolvem, de acordo com as Figuras 9 (b) e 9 (c). Assim, nas regiões de aproximação entre os grãos de areia e das frações de argila e silte foram formadas ligas argilosas altamente consolidada, que define fundamentalmente a capacidade dos solos em suportar cargas.

\section{CONSIDERAÇÕES FINAIS}

O método USEPA 350 mostrou-se eficaz para a abertura das amostras de solos, proporcionando a quantificação de $\mathrm{Pb}$ via análise voltamétrica de redissolução anódica com eletrodo de mercúrio.

A técnica voltamétrica de redissolução anódica utilizando eletrodo de mercúrio, mostrou-se satisfatória e provou ter um baixo limite de detecção $\left(0,0173 \mu \mathrm{mol} \mathrm{L}^{-1}\right)$ sendo apta em análises de amostras de solo contendo concentrações de metais extremamente baixas.
Os parâmetros experimentais otimizados: volume da amostra e tempo de pré-concentração selecionados, foram $2 \mathrm{~mL}$ e $30 \mathrm{~s}$, respectivamente, uma vez que demonstraram um maior incremento na magnitude de corrente e foram suficientes para a realização das análises de $\mathrm{Pb}$.

Os possíveis interferentes $(\mathrm{Zn}, \mathrm{Cd}$ e $\mathrm{Cu}$ não apresentaram diferenças significativas nos valores de corrente e deslocamento de potencial para a determinação do analito em interesse. Verificou-se também que não houve interferência de matéria orgânica.

A concentração de $\mathrm{Pb}$ nas amostras de solo coletadas na área de suposta falha geológica encontraram-se na faixa de $10^{-6}$ mol L $\mathrm{L}^{-1}$ enquanto que a concentração nos perfis coletados em locais distantes da falha geológica estavam na faixa de $10^{-8} \mathrm{~mol} \mathrm{~L}^{-1}$, forte indicativo sobre a influência da emanação de $\mathrm{Rn}$ na concentração de $\mathrm{Pb}$.

Os dados obtidos através das análises granulométricas revelaram que os solos coletados na área de suposta falha geológica são classificando-os em classes texturais Franco Arenoso e Franco Argilo Arenoso. As porcentagens da fração argila variam de 9,4 a $28,4 \%$ e estão restritamente ligadas à variação de concentração de chumbo nos diferentes tipos de solos.

As imagens obtidas através do MEV indicaram a sedimentação de partículas 
grossas e finas simultaneamente, formando aglomerados com uma estrutura muito frágil e solta, com grande volume de vazios, que podem ser ocupados por água e ar, onde o átomo de $\mathrm{Rn}$ pode ser incrustado e sofrer decaimento até o átomo de $\mathrm{Pb}$.

\section{AGRADECIMENTOS}

Os autores agradecem a Fundação de Amparo à Pesquisa do Estado de São Paulo FAPESP e ao Conselho Nacional de Pesquisa CNPq.

\section{REFERÊNCIAS}

ALBERT, H. P. Trace elements in soils. [s.I.]: Elsevier, 1977.

ALLEONI, L. R. F. et al. Components of surface charge in tropical soils with contrasting mineralogies. Soil Science, v.174, n.11, p.629638, 2009.

ALMEIDA, A. M. Determinação voltamétrica de molibdênio (VI) utilizando um sistema ternário homogênio de solventes. 2003. Tese (Doutorado) - Universidade Estadual de Campinas, Instituto de Química.

BAIRD, C. Química Ambiental. Bookman, 2 ed, p. 403-441, 2002.

BALCAZAR, $M$. et al. Geothermal-energy prospecting in El-Salvador. Nuclear Tracks and Radiation Measurements, v.22, n.1-4, p.273-276, 1993.

CHAUVEL, A. Iniciação à análise microscópica dos solos. USP: Piracicaba, 1979.

EMBRAPA. Manual de análises químicas de solos, plantas e fertilizantes. Brasília:

Embrapa, 1999.
EMBRAPA. Sistema Brasileiro de Classificação de Solos. Rio de Janeiro: Centro Nacional de Pesquisa de Solos, 2006.

FUSHIMI, M.; NUNES, J. O. R. Principais classes de solos do município de Presidente Prudente-SP: identificação e caracterização. Boletim Goiano de Geografia, p. 45-58, 2012.

MELO, V. F. Z.; ANDRADE, A.M.; BROSKA, C.Z. Chumbo em solos às margens de estradas na região metropolitana de Curitiba. Revista Acadêmica de Ciência Agrária e Ambiental, v. 8 , n. 1, p. 45-57, 2010.

OLSZOWY, H. T. P. et al. Trace element concentrations in soils from rural and urban areas of Australia. Australian Health Commission, v. 4, 1995.

SANTOS, L. J. C. B. J.; GRIMALDI, M.; CASTRO, S. S. Utilização do Microscópio Eletrônico De Varredura (MEV) para o reconhecimento de revestimentos argilosos. Boletim Paranaense de Geociências, v.53, p.35-43, 2003.

RAMSAY, J. G.; HUBER, M. I. The techniques of modern structural geology. London:

Academic Press, 1987.

ROSS, J. L. S.; MOROZ, I. C. Mapa geomorfológico do Estado de São Paulo. Revista do Departamento de Geografia, v.10, 1996.

TEIXEIRA, W. et al. Decifrando a Terra. São Paulo: Oficina do Texto, 2000.

UNSCEAR. Sources and Effects of lonizing Radiation. United Nations scientific committee on the effects of atomic radiation. New York: United Nations Sales Publication, 2000. (Report to the General Assembly, with Scientific Annexes, v.II)

USEPA. Method 3050 acid digestion of sediments. USA: Sludges and Soils, 1988. 
Quantificação de chumbo em solos.

XIAN, X. Effect of chemical forms of Cadmium, Zinc, and lead in polluted soils on their uptake by cabbage plants. Plant and

Soil, v.113, n.2, p.257-264, 1989. 